Brazilian Journal

of Chemical

ISSN 0104-6632

Engineering

Printed in Brazil

www.abeq.org.br/bjche

Vol. 34, No. 02, pp. 541 - 555, April - June, 2017

dx.doi.org/10.1590/0104-6632.20170342s20150520

\title{
CFD SIMULATION OF AN INDUSTRIAL REACTOR FOR THERMAL CRACKING OF 1,2-DICHLOROETHANE
}

\author{
T. C. L. de Oliveira ${ }^{1 *}$, A. T. Pereira Neto ${ }^{1}$, \\ J. J. N. Alves ${ }^{1}$ and A. A. de Morais Júnior ${ }^{2}$ \\ ${ }^{1}$ Laboratory of Numerical Experimentation of Processes, Chemical Engineering Department, Federal University of Campina Grande, \\ Avenue Aprígio Veloso, 882, 58429-100, Campina Grande, Paraíba, Brazil. \\ Phone: +55839616 9580, +558321011518 \\ Email: tallescaio@hotmail.com \\ Mailing address: Rua Maria de Lurdes Crispim 521, Apartment 04 \\ 58429-090, Universitário, Campina Grande, Paraíba, Brazil \\ ${ }^{2}$ Federal University of Paraíba, Chemical Engineering Department, \\ 58051-900, João Pessoa, Paraíba, Brazil
}

(Submitted: August 21, 2015; Revised: January 19, 2016; Accepted: February 28, 2016)

\begin{abstract}
The vinyl chloride monomer (VCM) is commercially produced on a large scale by thermal cracking of 1,2-dichloroethane (EDC) in a tubular reactor immersed in a furnace. Computational fluid dynamics (CFD) was used to simulate and predict the performance of an industrial reactor. The reactor conversion as well as the behavior of several process variables such as pressure, temperature, velocity and concentration of components through the reactor were predicted in this work. The results were compared with industrial data and are in agreement with them.
\end{abstract}

Keywords: Thermal Cracking, CFD, 1,2-Dichloroethane, Tubular Reactor.

\section{INTRODUCTION}

The vinyl chloride monomer (VCM) is the basic feedstock for the manufacture of polyvinyl chloride (PVC) used for a variety of purposes in industry. VCM is commercially produced on a large scale by pyrolysis of 1,2-dichloroethane (EDC) in industrial furnaces, producing anhydrous hydrogen chloride as byproduct, according to the following reaction:

$$
\mathrm{C}_{2} \mathrm{H}_{4} \mathrm{Cl}_{2(\mathrm{~g})} \rightarrow \mathrm{C}_{2} \mathrm{H}_{3} \mathrm{Cl}_{(\mathrm{g})}+\mathrm{HCl}_{(\mathrm{g})}
$$

The typical range of operational conditions of these reactors are: residence time of 10-30 s, pressure of 1.013252.0265 MPa, and gas temperature at around $773.15 \mathrm{~K}$, resulting in an EDC conversion of 50-60\% (Borsa , 1999).

A pyrolysis process for EDC cracking is illustrated in Figure 1. The fuel gas feeds a large isolated furnace lined with refractory bricks. Burners are mounted on the side walls to achieve the desired operating temperature. The EDC stream passes through stainless steel tubes inmersed inside the furnace where the reactions producing $\mathrm{VCM}, \mathrm{HCl}$ and by-products occur. The effluent gas has its temperature reduced to minimize the formation of byproducts.

Several works performing 1-D modeling and simulation of cracking reactors have been reported in the literature. Sundaram and Froment (1979) performed simulation of thermal cracking of ethane aiming to investigate the effect of coke deposition on the wall on reactor performance. A similar study was conducted by Plehiers et al. (1990) for

*To whom correspondence should be addressed 


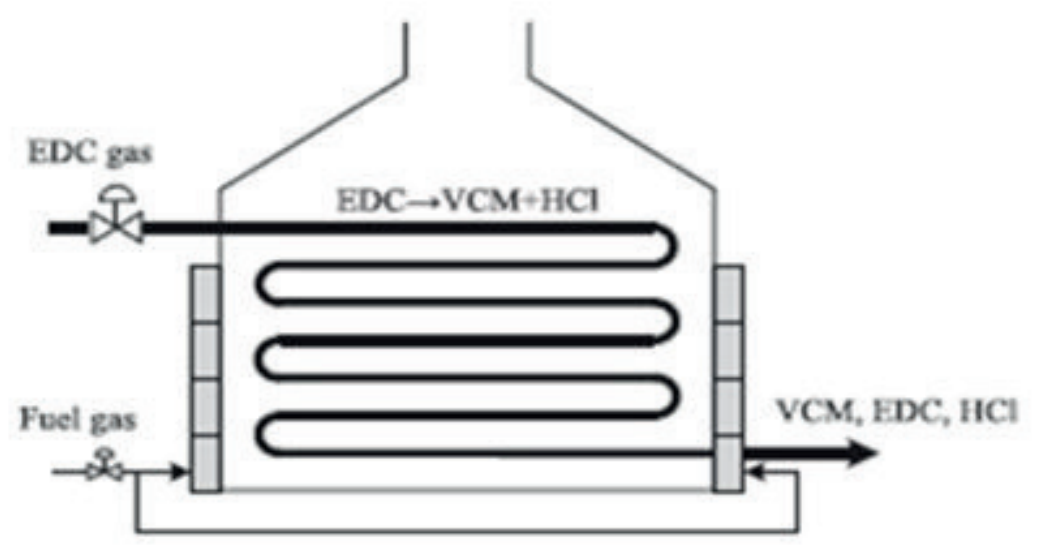

Figure 1. Pyrolysis Process (reproduced with permission from Panjanpornpon et al., 2012).

pyrolysis of propane. Ranzi et al. (1992) studied the effect of coke deposition on the pyrolysis of EDC also using an unidimensional reactor model.

Li et al. (2013) used modeling and simulation of an EDC pyrolysis furnace aiming to study two important aspects: adding $\mathrm{CCl}_{4}$ as cracking promoter and the allocation of fuel gas injection in the combustion chamber in order to understand its benefits on the cracking process. The results showed that the addition of $\mathrm{CCl}_{4}$ causes a significant increase in EDC conversion; however, it increases the coke formation, decreasing the efficiency of the furnace and shortening the operation time. The authors concluded that, for economic benefits, the optimal concentration of $\mathrm{CCl}_{4}$ is $100 \mathrm{ppm}$, and the optimal fuel gas allocation factor 0.36 to guarantee a long campaign and a high average conversion.

The 1-D model has the limitation of not considering the radial gradients, which means a perfect radial dispersion, resulting in an ideal plug flow reactor model. More accurate predictions can be obtained by using 2-D or full 3-D models for simulating industrial furnaces, for which several works in the literature have used CFD techniques.

Yang and Cao (2002) performed a two-dimensional modeling of EDC thermal cracking. The results showed a significant variation of temperature and reaction rate in the radial direction. The model could satisfactorily predict the EDC conversion, VCM selectivity, pressure, and temperature profiles at the outlet of the reactor coil.

Oprins et al. (2003) simulated a cracking furnace by using a 3D CFD model with the aim of studying the pressure and flow fields in the combustion chamber, and it was concluded that the reactor has little effect on the flow fields inside the combustion chamber.

Xingying (2004) simulated the furnace radiation zone for the cracking of ethylene by using CFD.

Li et al. (2012) performed a 1-D model simulation of the reactor using the Lobo-Evans method. The 1-D model was used for analysis and optimization of the reactor outlet temperature and fuel gas allocation. CFD simulations of the furnace-reactor were used to validate the results obtained. CFD simulations provided information on process variable such as turbulence, temperature and mass concentration distributionin the combustion chamber of the furnace.

Zhang et al. (2013) simulated the thermal cracking of propane using CFD techniques in order to investigate the behavior of the process variables.

Most of the works on CFD aim to describe the phenomena occurring in the furnace, not approaching in more detail inside the reactor. However, the pyrolysis reaction inside the reactor directly affects important process variables such as yield, cost, and quality of cracking products. This work consists in CFD modeling and simulation of the reactor of an industrial EDC cracking furnace in order to obtain the behavior of the main variables involved in the process such as pressure, temperature, concentration and velocity. One contribution of this work is to link the fluid flow inside the reactor to the chamber temperature outside the reactor through the wall boundary condition without needing to include the tube wall itself as being part of the domain, thus eliminating the mesh in the wall reactor, which reduces the size of the system of equations to be solved. The model was validated with industrial data as well as compared to the 1-D model and can be used to define new optimal operational conditions.

\section{MATHEMATICAL MODEL}

The mathematical model is based on the mass, momentum, and energy conservation laws (Bird et al. , 2002):

\section{Continuity Equation}

$$
\frac{\partial \rho}{\partial t}+\nabla \cdot(\rho \vec{v})=0
$$




\section{Momentum conservation}

$$
\frac{\partial}{\partial t}(\rho \vec{v})+\nabla \cdot(\rho \vec{v})=\nabla \cdot \mu_{e f f}\left(\nabla \vec{v}+\nabla \vec{v}^{T}\right)+\rho \vec{g}-\nabla P
$$

The standard k-epsilon turbulence model (Jones and Launder, 1972) was used to calculate the turbulent viscosity of the fluid. This model is widely used for industrial applications due to its good convergence rate, relatively low memory requirements and accuracy. Several works in the literature used the standard k-epsilon for turbulent flows in pipes (Sugiharto et al., 2013; Zambrano, 2015).

\section{Individual Component Mass Conservation}

$$
\frac{\partial}{\partial t}\left(\rho Y_{i}\right)+\nabla \cdot\left(\rho \vec{v} Y_{i}\right)=\nabla \cdot\left(\Gamma_{i M} \nabla Y_{i}\right)+R_{i}
$$

\section{Energy Conservation}

$$
\frac{\partial}{\partial t}\left(\rho c_{p} T\right)+\nabla \cdot\left(\rho \vec{v} c_{p} T\right)=\nabla \cdot\left(\lambda_{e f f} \nabla T\right)+S_{E}+\Phi_{f r}
$$

\section{Boundary Conditions}

\section{Inlet}

All variables were prescribed at this boundary except the pressure, which was extrapolated from the flow domain.

\section{Outlet}

The continuity condition was used (derivative null with respect to the normal to the boundary in the direction of flow), except the pressure, which had its value specified at this boundary.

\section{Wall}

The impermeable, non-slip condition was used for velocity and species normal mass flow. For temperature, an energy balance at the interface wall/chamber (Equation 6) was used in order to calculate the wall outside tube skin temperature (Incropera, 2007).

$$
\frac{T_{w}-T_{s}}{R_{w}}=\frac{A_{s} \sigma\left(T_{s}{ }^{4}-T_{p}{ }^{4}\right)}{\frac{1-\varepsilon_{s}}{\varepsilon_{s}}+\frac{1}{F_{s p}}+\frac{A_{s}\left(1-\varepsilon_{p}\right)}{A_{p} \varepsilon_{p}}}
$$

where

$$
R_{w}=\frac{\ln \left(\frac{\mathrm{r}_{\mathrm{s}}}{\mathrm{r}_{\mathrm{in}}}\right)}{2 \pi \mathrm{k}_{\mathrm{w}} L}
$$

is the wall conductive resistence.

The right side of Equation 6 can be rewritten in the standard generalized Stefan-Boltzman equation as follows:

$$
\frac{T_{w}-T_{s}}{R_{w}}=A_{s} \epsilon F_{p s} \sigma\left(T_{s}{ }^{4}-T_{p}{ }^{4}\right)
$$

where the emissivity function is given by:

$$
\epsilon=\left[\frac{F_{p s}\left(1-\varepsilon_{S}\right)}{\varepsilon_{S}}+\frac{A_{S}}{A_{p}}\left(1+\frac{F_{p s}\left(1-\varepsilon_{p}\right)}{\varepsilon_{p}}\right)\right]^{-1}
$$

Equation 8 is a polynomial function in Ts and can be rewritten as follows:

$$
T_{s}^{4}+\mathrm{b} T_{s}+c=0
$$

where $\mathrm{b}$ and $\mathrm{c}$ are given by:

$$
\begin{gathered}
\mathrm{b}=\frac{\mathrm{k}_{\mathrm{w}}}{\mathrm{r}_{\mathrm{s}} \ln \left(\frac{\mathrm{r}_{\mathrm{s}}}{\mathrm{r}_{\mathrm{in}}}\right) \epsilon \sigma \mathrm{F}_{\mathrm{ps}}} \\
\mathrm{c}=-\left(\mathrm{T}_{\mathrm{p}}{ }^{4}+\mathrm{bT}_{\mathrm{w}}\right)
\end{gathered}
$$

The skin temperature Ts is then obtained by solving Equation 10 for Ts. As can be seen, Equation 10 is a 4-degree polynomial function having four roots.

It is worth mentioning that $\mathrm{T}_{\mathrm{w}}$, the temperature on the inner surface of the reactor wall is obtained from the flow domain at the previous iteration.

The only root of the 4-degree polynomial function (Equation 10) having physical meaning (value between the inner surface temperature and wall chamber temperature) is the following:

$$
T_{s}=-\frac{1}{2} \sqrt{2 y}+\frac{1}{2} \sqrt{-2 y+2 b / \sqrt{2 y}}
$$

where:

$$
y=\sqrt[3]{\frac{b^{2}}{16}+\sqrt{\frac{b^{4}}{64}-c^{3}}}+\sqrt[3]{\frac{b^{2}}{16}-\sqrt{\frac{b^{4}}{64}-c^{3}}}
$$


Is the real positive root of the auxiliary 3-degree polynomial function:

$$
\mathrm{y}^{3}-\mathrm{cy}-\frac{b^{2}}{8}=0
$$

Thus, from an energy balance at the inner wall surface, one of the boundaries of the domain, the heat flux at this boundary is:

$$
-\left.k_{M} \frac{\partial T}{\partial r}\right|_{r=r_{i n}}=\frac{A_{s} h_{r}\left(T_{s}-T_{p}\right)}{A_{i}}
$$

where the coefficient of heat transfer by radiation between the combustion chamber and the external surface of the reactor was calculated from Equation 17 (Incropera, 2007).

$$
h_{r}=\epsilon F_{p s} \sigma\left(T_{s}+T_{p}\right)\left(T_{s}^{2}+T_{p}^{2}\right)
$$

The view factor $\mathrm{F}_{\mathrm{ps}}$, defined as the fraction of radiation that leaves the inner sidewall of the firebox and intersects the outer surface of the reactor, was calculated from Equation 18 (Incropera, 2007), the view factor between an infinite plate and a cylinder.

$$
F_{p s}=1-\left[1-\left(\frac{D}{s}\right)^{2}\right]^{1 / 2}+\left(\frac{D}{s}\right) \tan ^{-1}\left[\left(\frac{s^{2}-D^{2}}{D^{2}}\right)^{1 / 2}\right]
$$

It is worth emphasizing that Equation (16) was the one implemented in Ansys ${ }^{\circledR}$ CFX as the wall boundary condition for heat transfer.

\section{Reaction kinetic and Heat Generation Rate}

The rates of EDC cracking and heat consumption due to the endothermic cracking reaction are calculated from Equations 19 and 20, respectively.

$$
\begin{aligned}
& R_{E D C}=\mathrm{KC}_{\mathrm{EDC}} \\
& S_{E}=R_{E D C} \Delta H_{r}
\end{aligned}
$$

The kinetic constant and the enthalpy of reaction are functions of temperature according to Equations 21 and 22, respectively (Fogler, 2000).

$$
\begin{gathered}
\mathrm{K}=\mathrm{A}_{\mathrm{j}} \mathrm{e}^{-\mathrm{E}_{\mathrm{aj}} / \mathrm{RT}} \\
\Delta \mathrm{Hr}=\Delta \mathrm{Hfi}+\int \Delta C_{p i} d T
\end{gathered}
$$

Although pyrolysis involves hundreds of reactions with molecular compounds and radicals (Borsa, 1999; Choi et al., 2001), in this work only the main cracking reaction has been considered due to the high VCM selectivity with values greater than $99 \%$ (Borsa, 1999). The activation energy and pre-exponential factor for reaction are 120750 $\mathrm{J} / \mathrm{mol}$ and $1.15107 \mathrm{~s}^{-1}$, respectively (Panjanporon et al., 2012).

\section{Physical Properties}

The physical properties of the components used in this study were obtained from Yaws (1999).

\section{Heat Capacity}

$$
\mathrm{C}_{\mathrm{pi}}=\mathrm{A}_{\mathrm{Ci}}+\mathrm{B}_{\mathrm{Ci}} \mathrm{T}+\mathrm{C}_{\mathrm{Ci}} \mathrm{T}^{2}
$$

Thermal Conductivity

$$
\mathrm{K}_{\mathrm{i}}=\mathrm{A}_{\mathrm{ki}}+\mathrm{B}_{\mathrm{ki}} \mathrm{T}+\mathrm{C}_{\mathrm{ki}} \mathrm{T}^{2}
$$

Enthalpy of Formation

$$
\mathrm{H}_{\mathrm{fi}}=\mathrm{A}_{\mathrm{Hi}}+\mathrm{B}_{\mathrm{Hi}} \mathrm{T}+\mathrm{C}_{\mathrm{Hi}} \mathrm{T}^{2}
$$

Dynamic Viscosity

$$
\mu_{\mathrm{i}}=\mathrm{A}_{\mathrm{V}_{1}}+\mathrm{B}_{\mathrm{Vi}_{1}} \mathrm{~T}+\mathrm{C}_{\mathrm{V}_{\mathrm{i}}} \mathrm{T}^{2}
$$

where $\mathrm{A}, \mathrm{B}$ and $\mathrm{C}$ with their respective sub-indices are constant correlations obtained through experimental data for each component. The mixture property is obtained from a mass average of the component properties.

\section{COMPUTATIONAL MODEL}

The reactor geometry consists of tubes with straight and curved sections as shown in Figure 2. The 3 points (5.0; 8.5; and $12.5 \mathrm{~m}$ ) highlighted in Figure 2 represents locations were the flow was analyzed to investigate the 
behavior of the variables in the radial direction. Geometry details and operating conditions are shown in Table 1 for the industrial reactor studied in this work. The temperature of the firebox wall of a typical EDC furnace is equal to 1053.15 K as reported in Schirmeister (2009), and this value was assumed in this work.

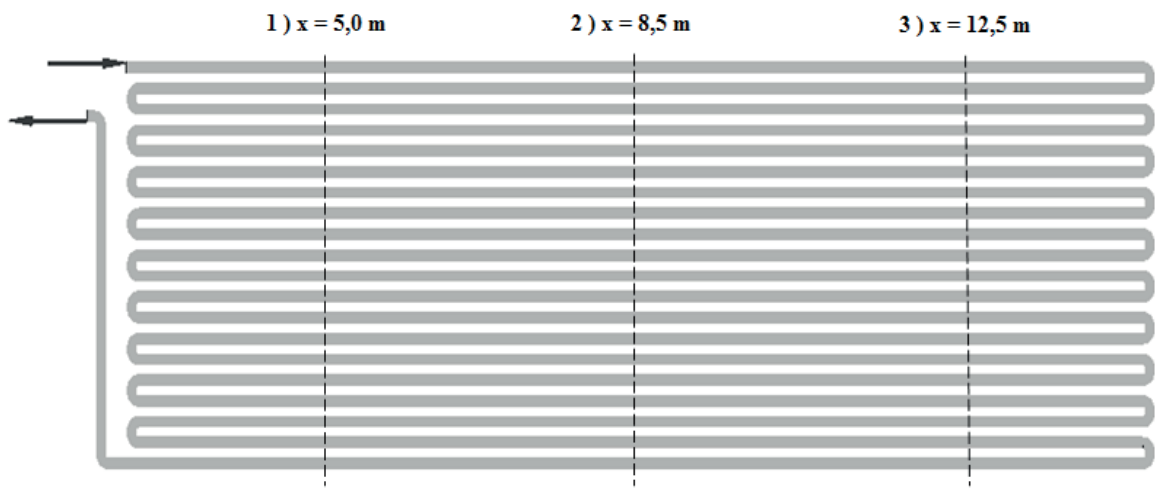

Figure 2. Reactor geometry.

Table 1. Typical Industrial Data

\begin{tabular}{cc}
\hline Parameter/variable & Value \\
\hline Inlet mass flow & $8.567[\mathrm{~kg} / \mathrm{s}]$ \\
\hline Inlet pressure & $2.07[\mathrm{MPa}]$ \\
\hline Outlet pressure & $1.93[\mathrm{MPa}]$ \\
\hline Inlet temperature & $523.15[\mathrm{~K}]$ \\
\hline Outlet temperature & $771.15[\mathrm{~K}]$ \\
\hline Tube length & $348.45[\mathrm{~m}]$ \\
\hline Curvature radius & $0.178[\mathrm{~m}]$ \\
\hline Length of the bends & $0.5[\mathrm{~m}]$ \\
\hline Number of the bends & $22[-]$ \\
\hline Reactor diameter & $0.15[\mathrm{~m}]$
\end{tabular}

The numerical mesh contains 1,036,408 hexahedral elements. The Mesh is shown in Figure 3 for different

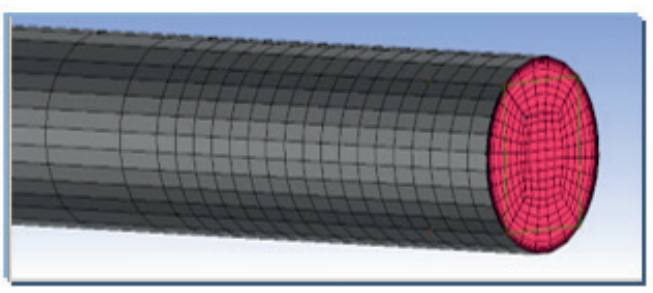

(a)

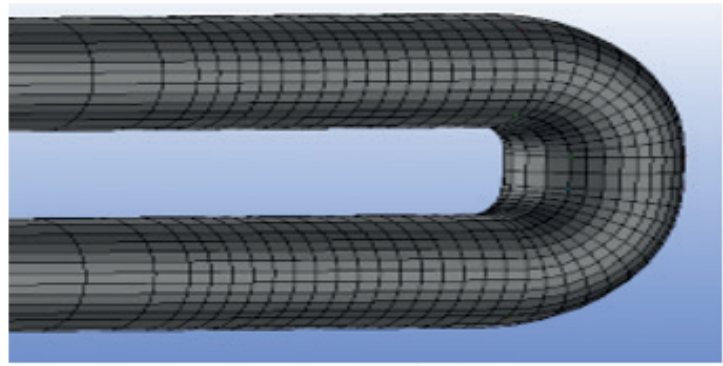

(c) regions in the reactor. The inlet, curves and outlet regions were refined to better capture the details of the flow.

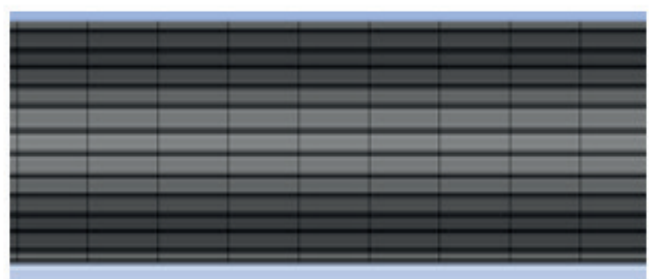

(b)

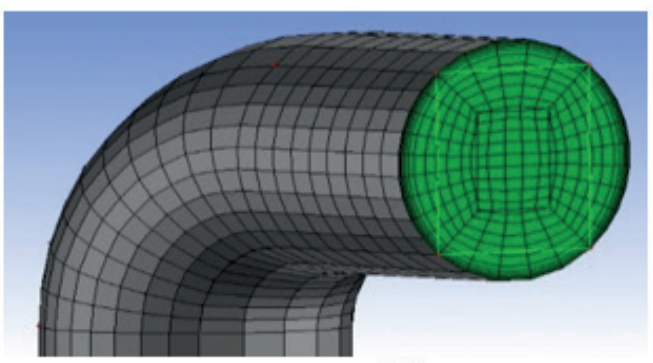

(d)

Figure 3. Mesh details: a) reactor inlet b) straight section; c) curves and d) reactor outlet. 
A mesh independence study was conducted to ensure that the results are not influenced by the mesh. Temperature and pressure were evaluated for different mesh sizes as shown in Figures 4 and 5, respectively.

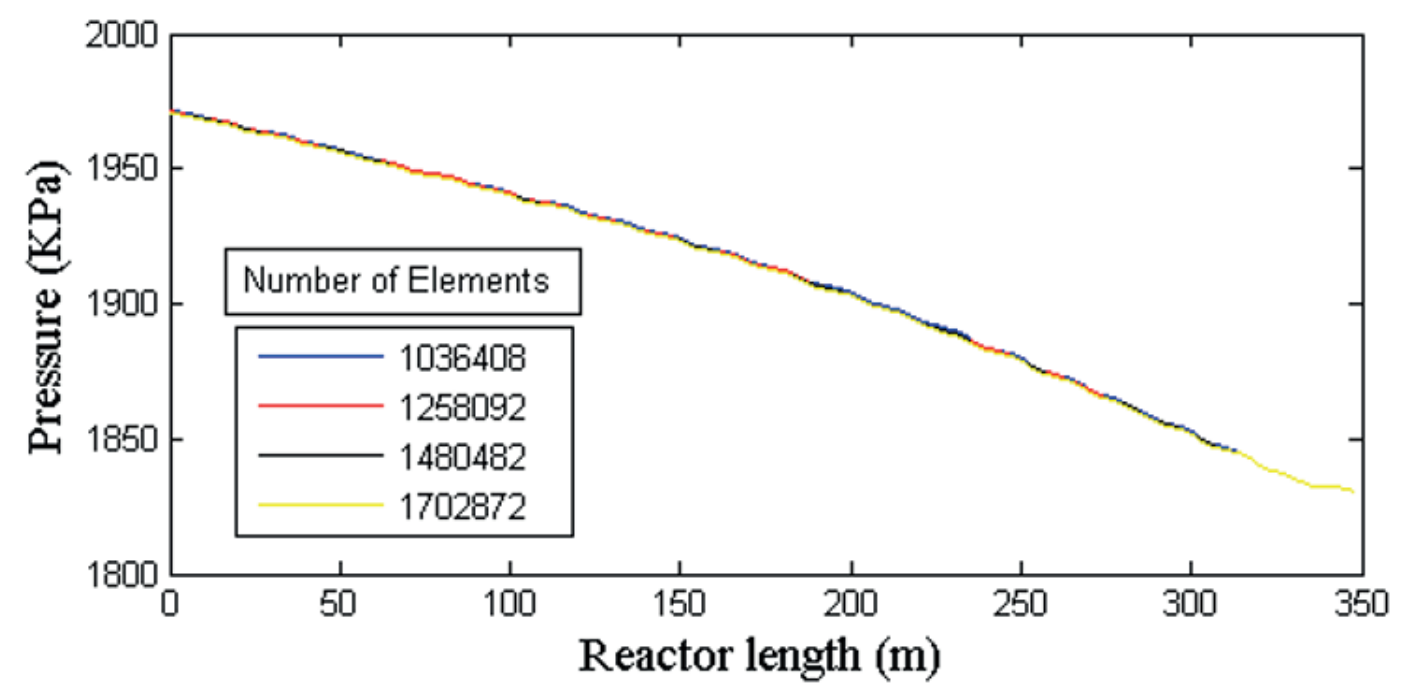

Figure 4. Pressure profile as a function of number of elements.

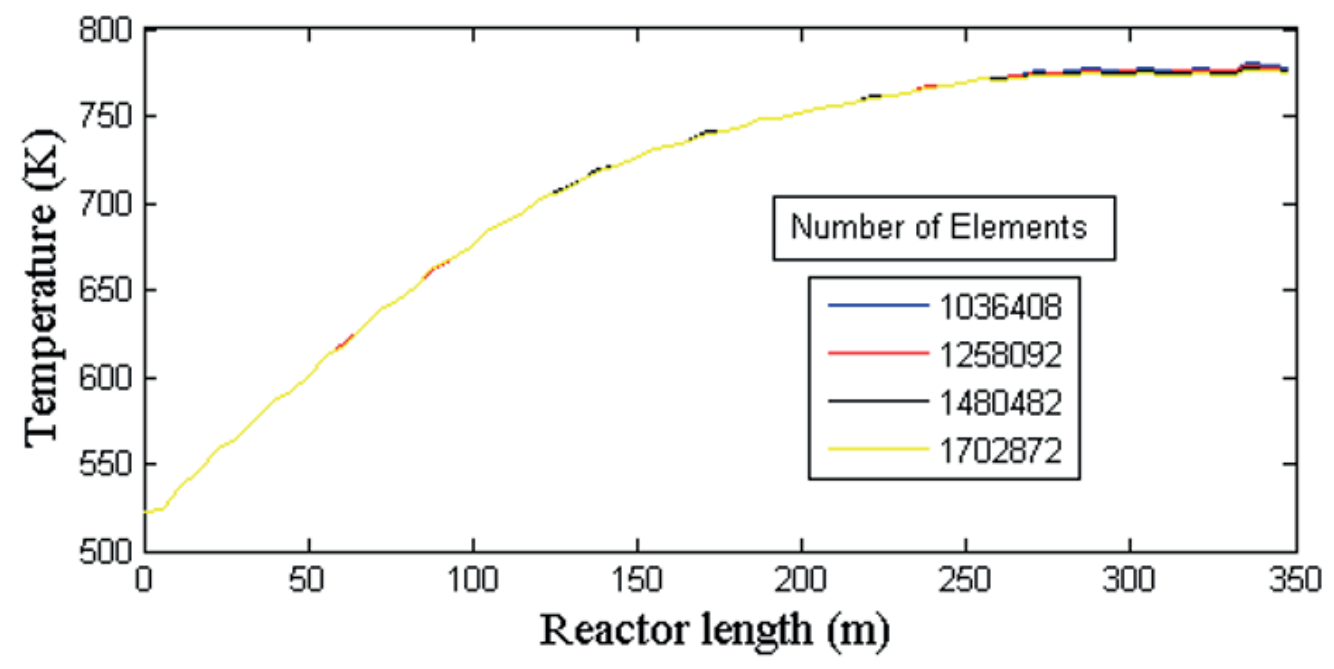

Figure 5. Temperature profile as a function of number of elements.

The simulations were conducted in steady state in Ansys ${ }^{\circledR}$ CFX software. Ansys ${ }^{\circledR}$ CFX software uses a hybrid finite-element/finite-volume approach for discretizing the conservation equations (Navier-Stokes, mass, energy, etc). As a finite volume method, it satisfies strict global conservation by enforcing local conservation over control volumes that are constructed around each mesh vertex or node. The finite element methodology is used to describe the solution variation (needed for various surface fluxes and source terms) within each element. The SIMPLE algorithm was used for pressure-velocity coupling and a high order hybrid interpolation scheme has been used (ANSYS CFXSolver Theory Guide,2009).

The simulations were performed on computer servers with an Intel ${ }^{\circledR}$ Xeon ${ }^{\circledR}$ E5-2400 processor with 8 cores. The residual convergence specified was $1 \times 10^{-4}$ and the simulation time is approximately 10 hours. 


\section{RESULTS AND DISCUSSION}

The EDC and VCM mass fraction profiles are shown in Figures 6 and 7 on a plane that intersects the center of the reactor. Initially, the gas is heated without reaction taking place in the first hundred meters of the reactor; the cracking of EDC start effectively after this initial heating length. A conversion of about $54 \mathrm{wt} \%$ of EDC was predicted from Figure 6 , for a selectivity of $27 \mathrm{wt} \%$ of $\mathrm{VCM}$, as can be seen from Figure 7.

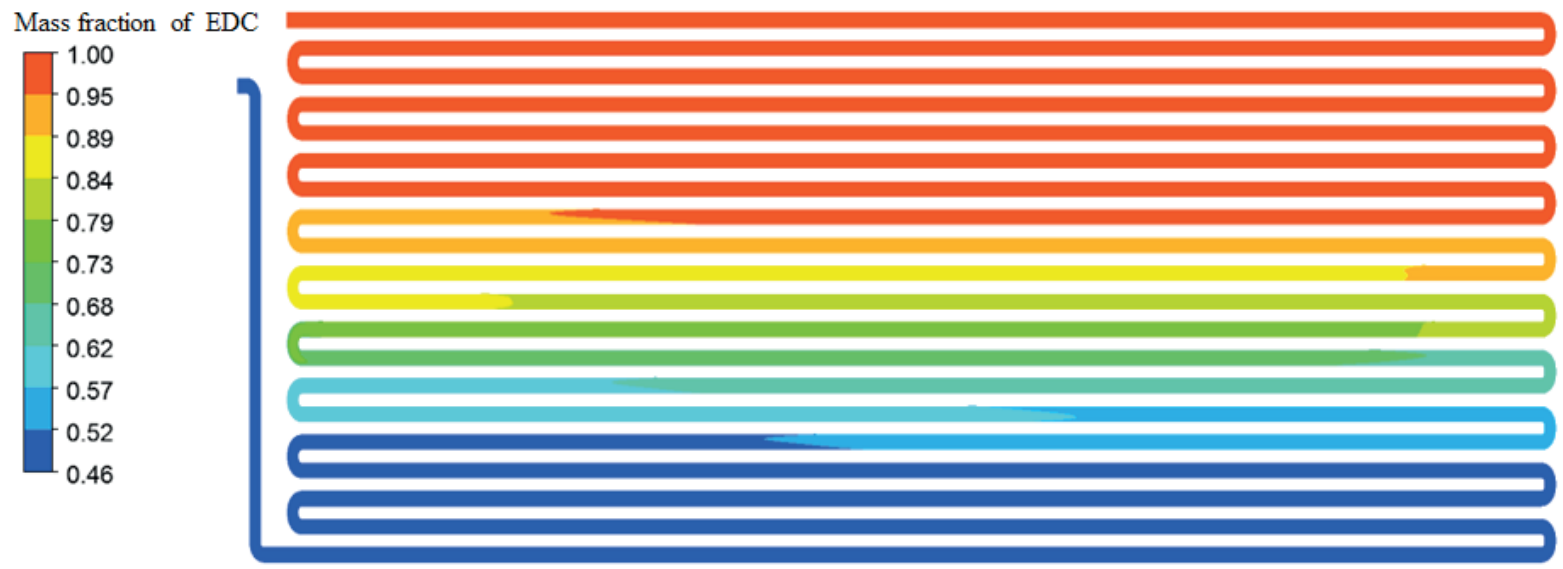

Figure 6. Mass fraction of EDC along the reactor.

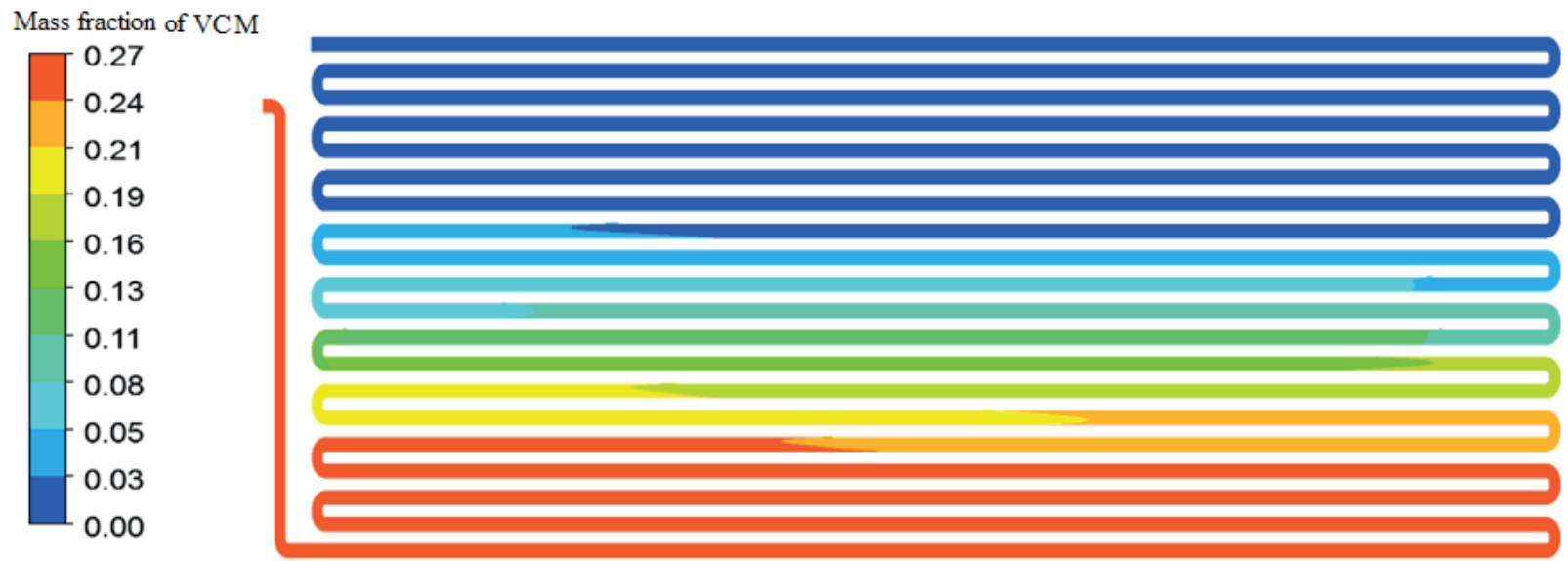

Figure 7. Mass fraction of VCM along the reactor.

The variation of pressure along the reactor caused by the loss of distributed load (stretch of straight pipe) and localized (curves in U) is illustrated in Figure 8, from which a total pressure drop of about $165 \mathrm{kPa}$ was predicted.

The inner surface temperature along the reactor wall is shown in Figure 9. As can be seen, despite the furnace wall temperature being constant, the predicted results obtained through CFD show a non-uniformity of the temperature on the inner surface of the reactor wall, with variations between nearby regions of approximately $30 \mathrm{~K}$ being observed.

The profiles of mass fraction of EDC and temperature at 3 cross sections are shown in Figures 10 and 11, respectively. The arrows in theses figures indicate the direction of flow. It can be observed from Figure 10 that the variation of the mass fraction of EDC in the axial and radial direction is initially small due to the fact that the fluid has not reached the temperature necessary to initiate cracking. Relevant reductions of the mass fraction of EDC are observed at the eighth cross section of plane 1 from the top of Figure 10, when the reaction of cracking starts taking place closer to the wall of the reactor, which is subjected to higher temperature than the center of the reactor.

The behavior of the temperature with the radial direction for the different planes analyzed illustrates the non-uniform heating throughout the cross section of the reactor, and the results have shown, as expected, higher temperatures near the wall and the lowest at the center of the tube according to Figure 11.

The velocity variation with the radial direction is illustrated in Figure 12. The higher velocity gradient close to the wall is typical for turbulent flow, where the flow is 

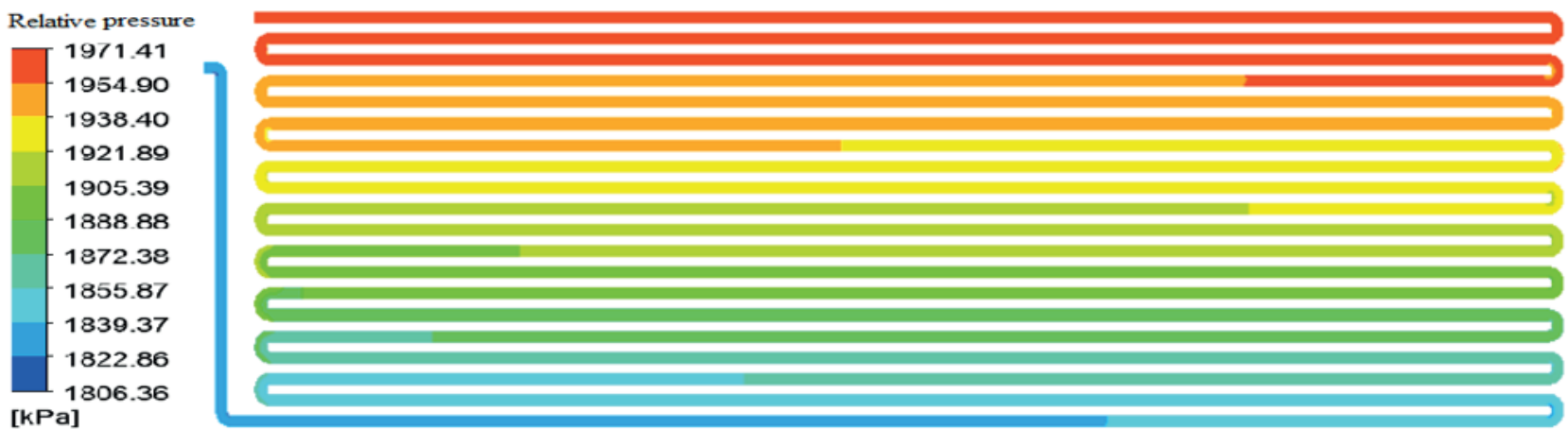

Figure 8. Pressure along the reactor.

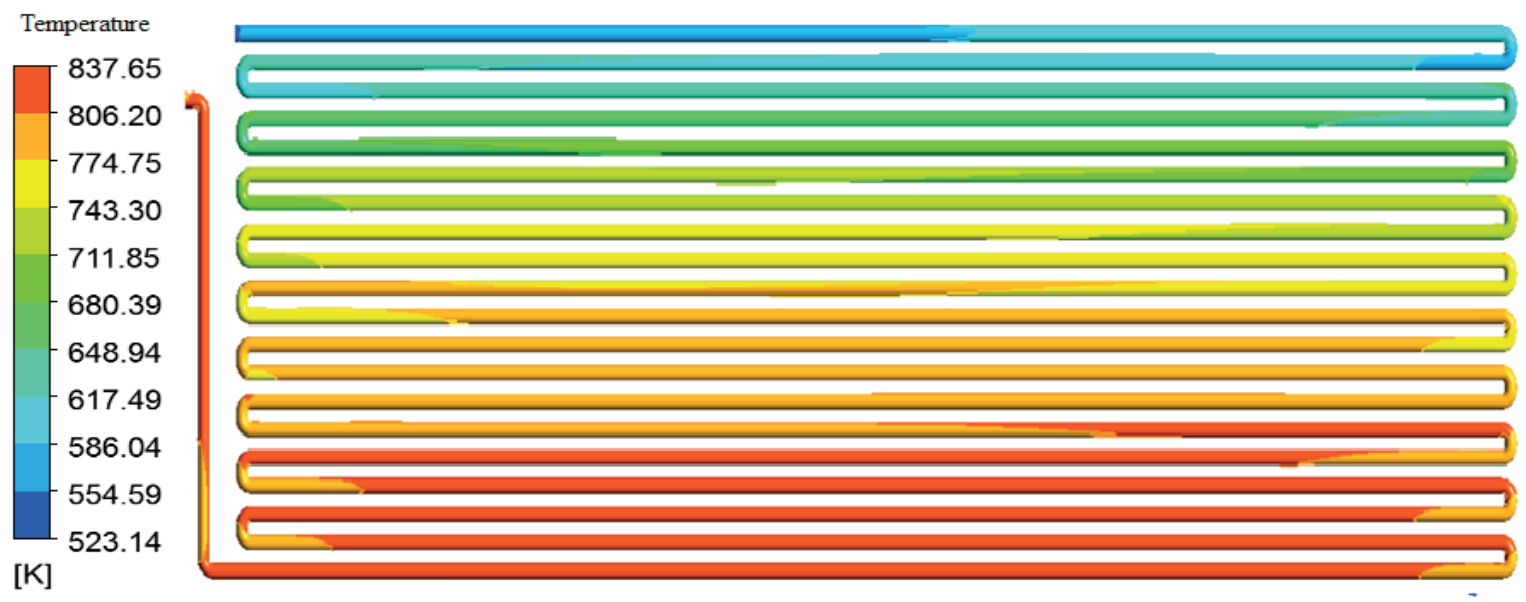

Figure 9. Temperature profile on the inner surface of the reactor.

laminar in a very thin layer close to the wall (the laminar sublayer) and zero on the wall. The velocity increases along the longitudinal direction of the reactor, initially due to the temperature increase causing an expansion of the gaseous mixture along the reactor, and secondly due to the beginning of the cracking reaction that increases the number gas molecules.

Line graphs of the main variables at the center line along the reactor are illustrated in Figures 13 to 17 , enabling a quantitative visualization of variables and also a comparison of the results with available industry data. In Figures 13 and 14, the results of the 1-D model for the EDC cracking, based on the model proposed by Plehiers (1990), were included for comparison. As can be seen from these figures the 1-D model results are in agreement with the CFD results, suggesting that the 1-D model is suitable for predicting the reactor performance.

During the first half pass of the reactor, the process gas temperature (reactants and products) rapidly increases because the absorbed heat is mainly used to increase the process gas temperature, as can be seen from Figure 13. The EDC cracking reaction occurs when the process gas temperature reaches about $690 \mathrm{~K}$. The process gas temperature slowly increases during the last half pass because most of the absorbed heat is used for the endothermic reaction.

The EDC mass fraction along the center line of the reactor is shown in Figure 14. The initial length of the reactor (about $100 \mathrm{~m}$ ) where no cracking reactions occurs due to insufficient temperature can be observed, as well as that at the end of the reactor (about $50 \mathrm{~m}$ ) where the rate of cracking is slow because reaction equilibrium is reached, as depicted in Figure 15. At the reactor outlet the EDC mass fraction is 0.4763 , corresponding to an EDC conversion of $52.37 \%$.

The reactor temperature and EDC mass fraction at the reactor center line from the CFD model are compared to the reactor temperature and EDC mass fraction from the 1-D model in Figures 13 and 14. As can be seen, the 1-D model and CFD models are in good agrement. It is worth mentioning that the diference between the two profiles is because the CFD results are those at the center line and not the average value as predicted by the 1-D model.

In the first part of the reactor the gas is accelerated 


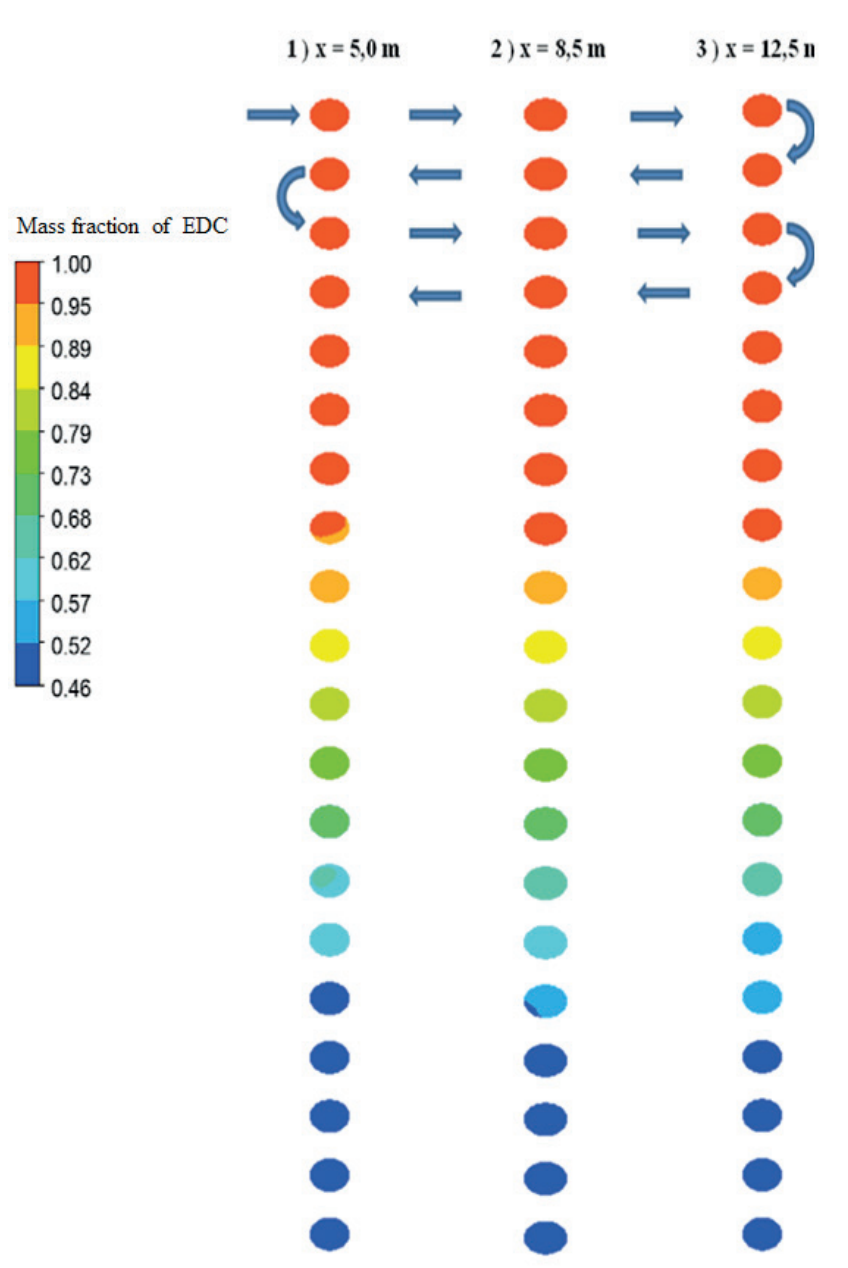

Figure 10. Profile of mass fraction of EDC in cross section in different planes along the reactor.

because the volume of the gas expands with increasing temperature. As the cracking reaction is initiated there is an increase in total volumetric flow, further increasing the gas velocity in relation to the heating period, as shown in Figure 16.

The pressure along the reactor center line is shown in Figure 17. The steps observed in Figure 17 correspond to the additional pressure drop due to the bends present in the reactor. It can also be observed that the pressure gradient is not constant due to additional factors affecting the pressure drop as, for example, temperature and density changes in the reactor.

The radial profiles were analyzed quantitatively on two lines at the outlet of the reactor shown in Figure 18.

The radial profiles of temperature, EDC mass fraction, and velocity at the outlet of the reactor taking as origin the center of the tube $(\mathrm{r}=0)$ are illustrated in Figures 19 to 21 aiming to evaluate the behavior of such variables. Temperature differences between the center and the wall of the tube were $9 \mathrm{~K}$ and $6 \mathrm{~K}$ for lines 1 and 2 as shown in Figure 19. The EDC mass fraction presents minimal

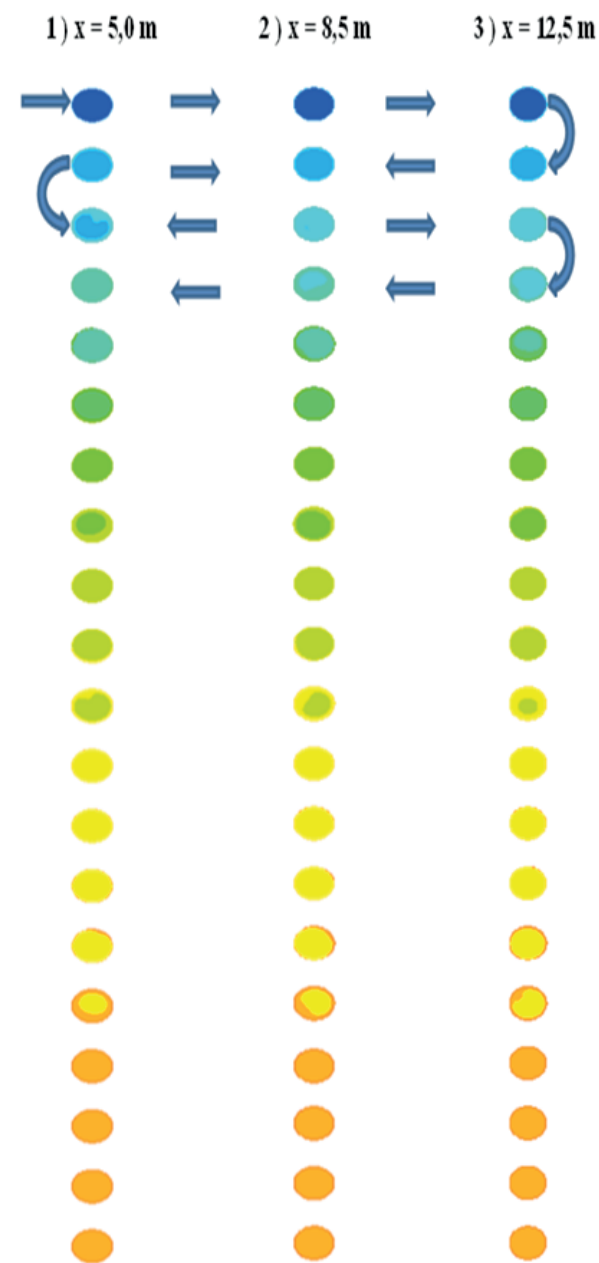

Figure 11. Temperature profile in cross-section in different planes along the reactor.

variation in the radial direction as shown in Figure 20. A typical velocity profile of turbulent flow can be seen in Figure 21, showing the turbulent core and the laminar sublayer close the wall. Summarizing, from Figures 19 to 21 a low dependence of the process variables with the angular position inside the reactor can be observed. It can also be seen that, in the radial direction, the gradients of the process variables are significant only closer to the wall of the reactor, approaching a plug flow behavior in the turbulent nucleus.

\section{CONCLUSIONS}

The modeling and simulation of a cracking reactor using CFD was successfully performed. The variables of the process were obtained, enabling a better understanding of the EDC cracking process. The results are in agreement with industrial data from an EDC plant in Brazil. The CFD results are also in good agreement with the 1-D model. Hence, for the previous reactor analysis and optimization, 


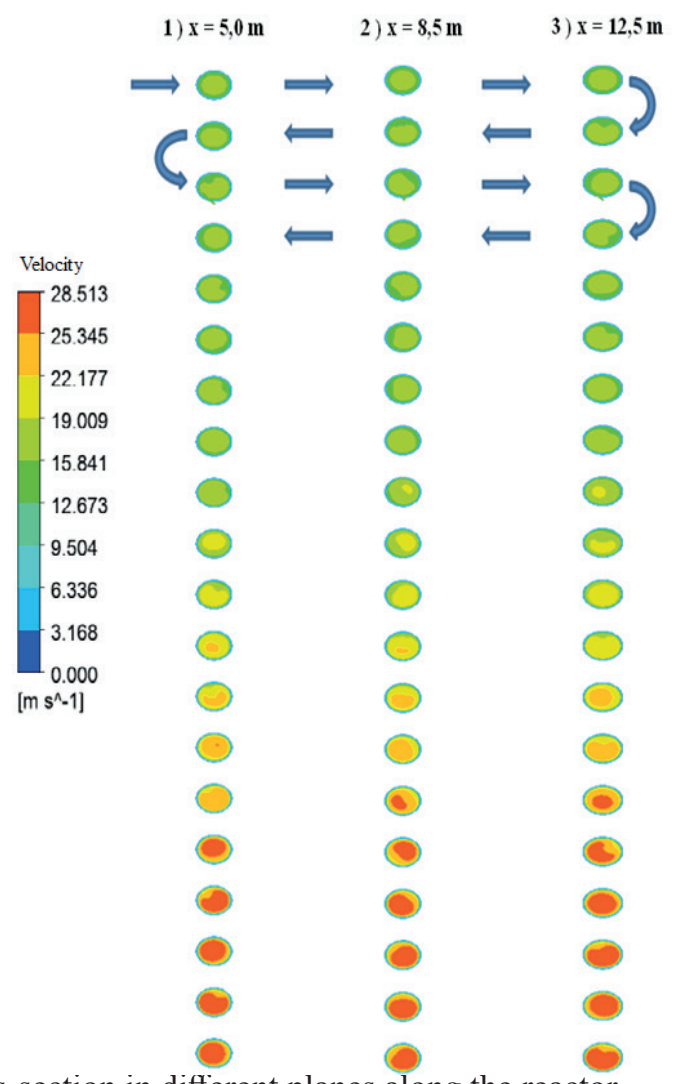

Figure 12. Velocity profile in cross-section in different planes along the reactor.

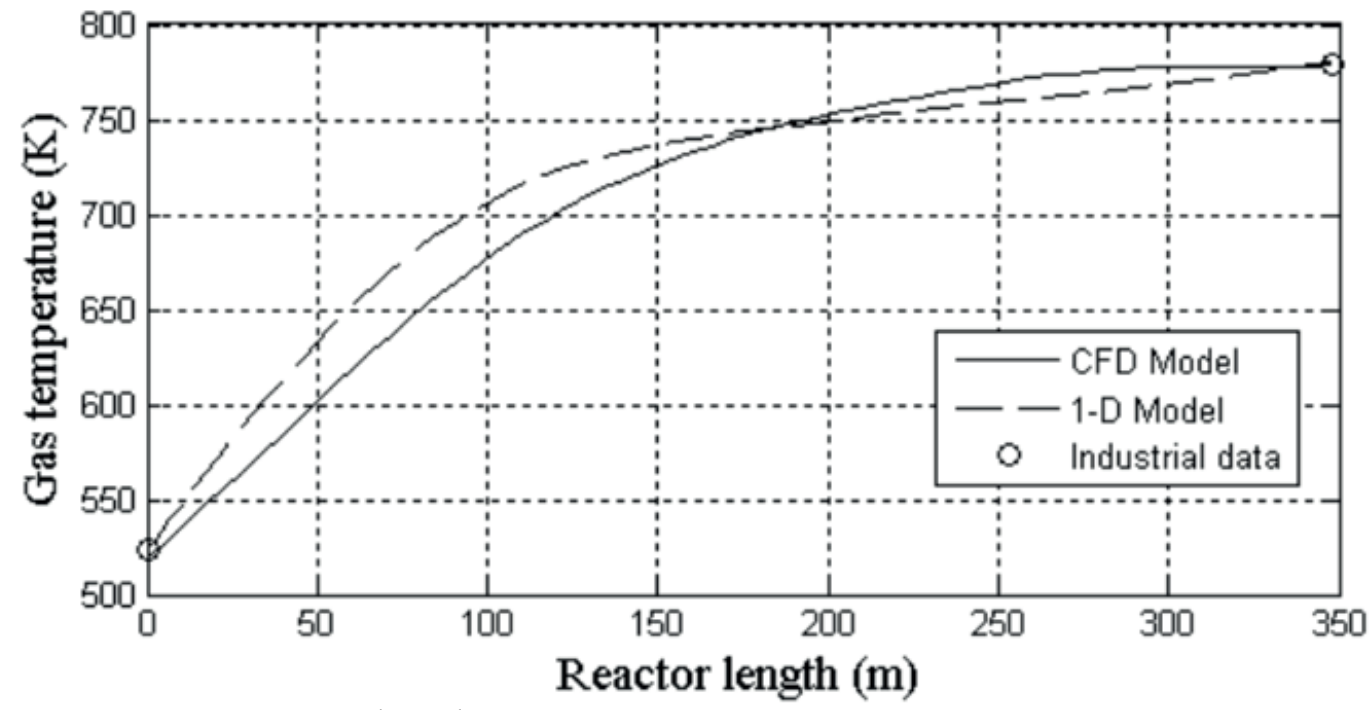

Figure 13. Process gas temperature along the reactor. 


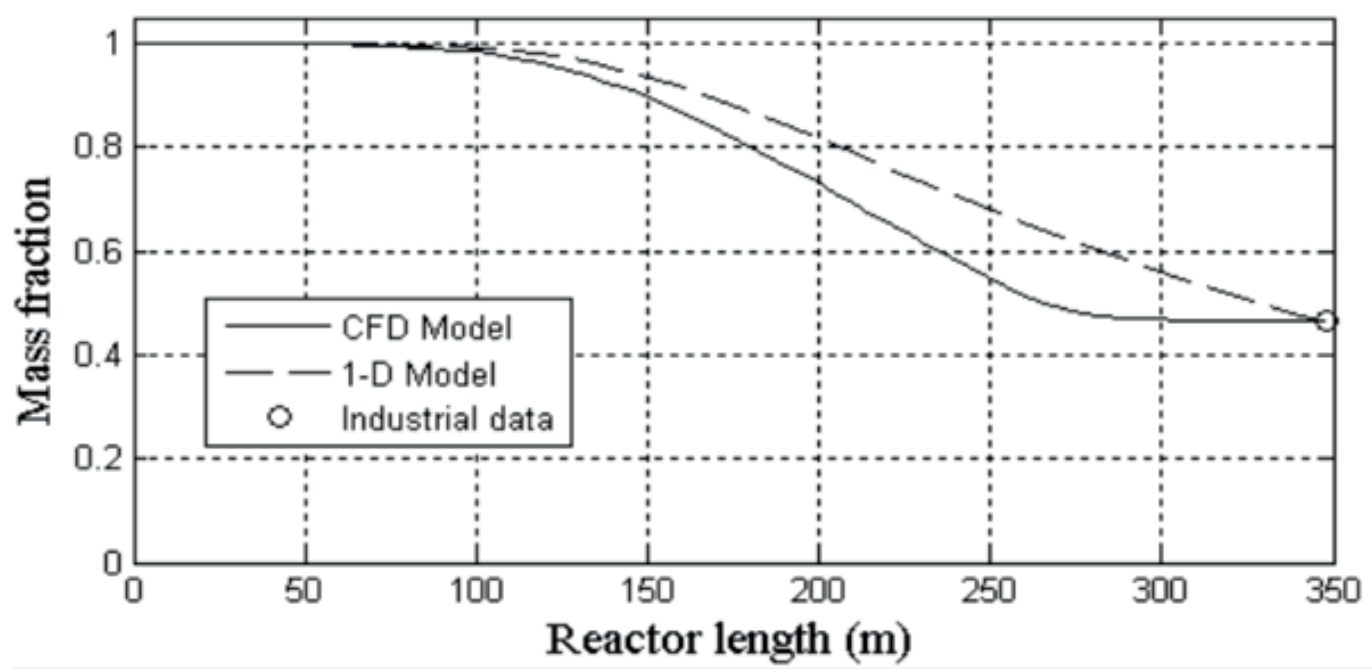

Figure 14. Mass fraction of EDC along the reactor.

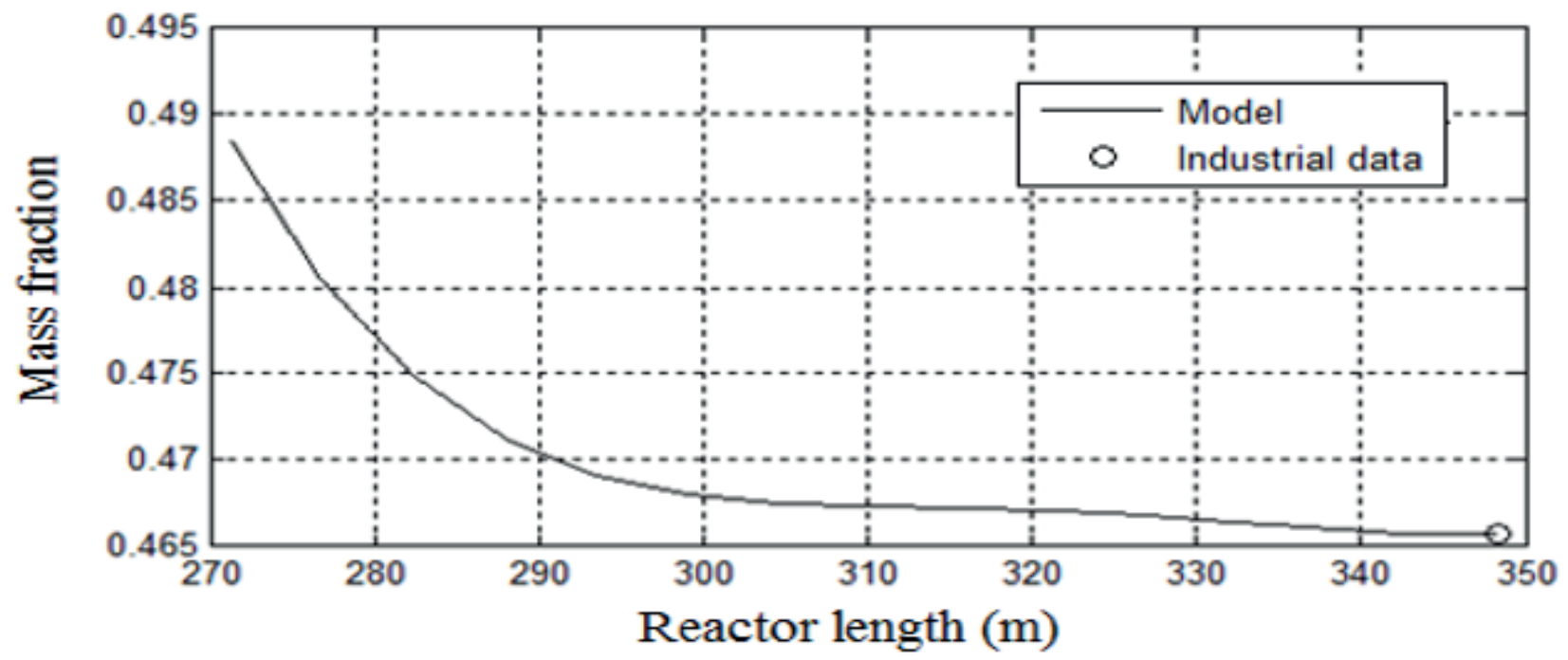

Figure 15. Mass fraction of EDC at the end of the reactor.

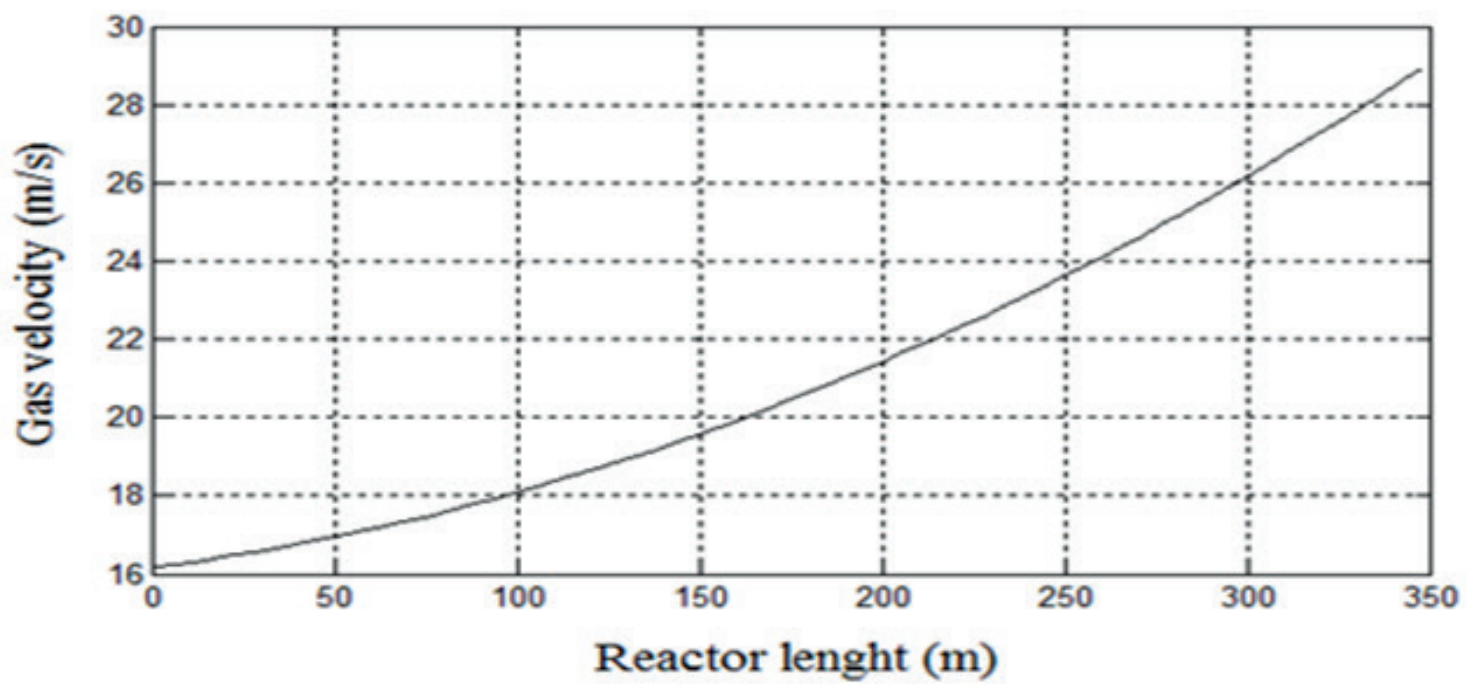

Figure 16. Gas velocity along the reactor (CFD model). 


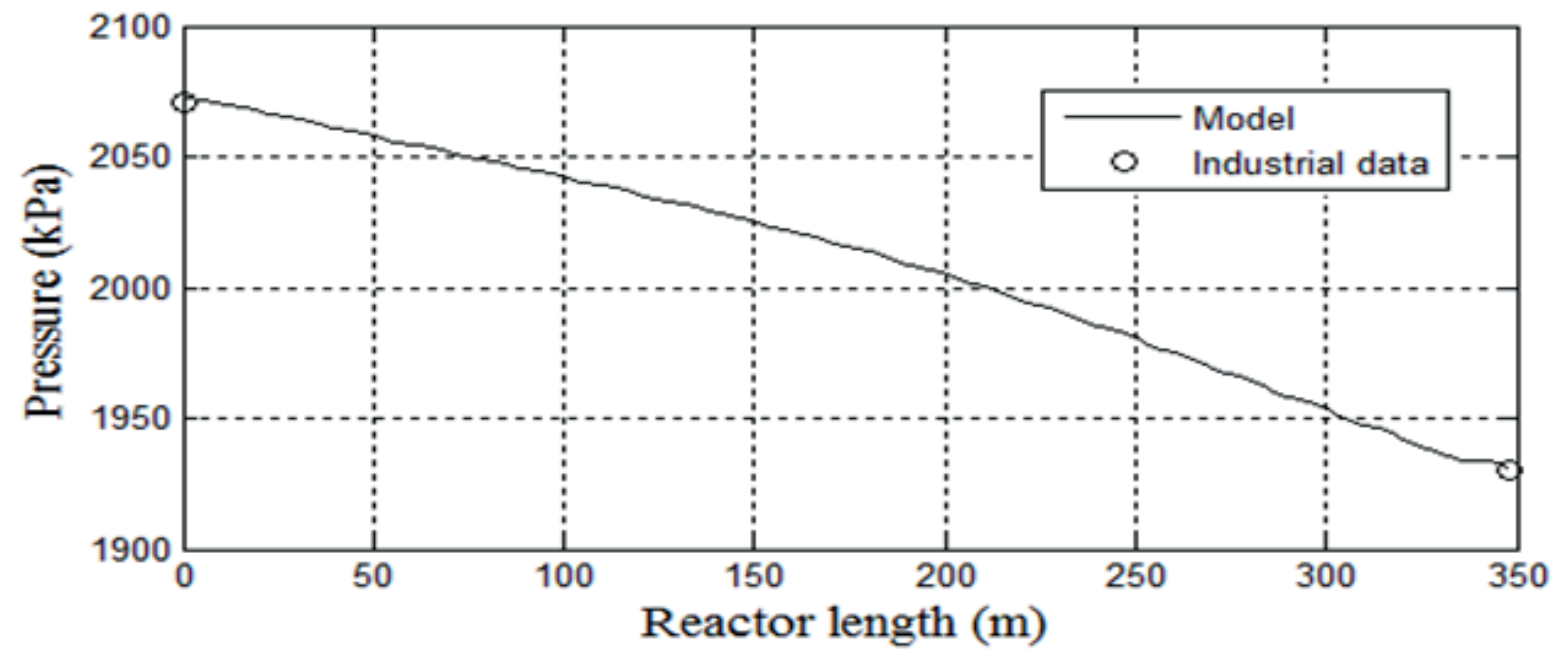

Figure 17. Pressure drop along the reactor (CFD model).

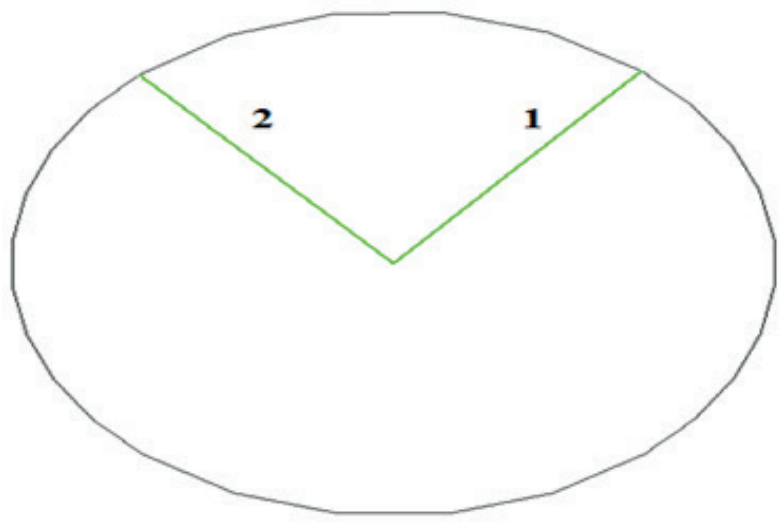

Figure 18. Radial lines at the exit of the reactor.

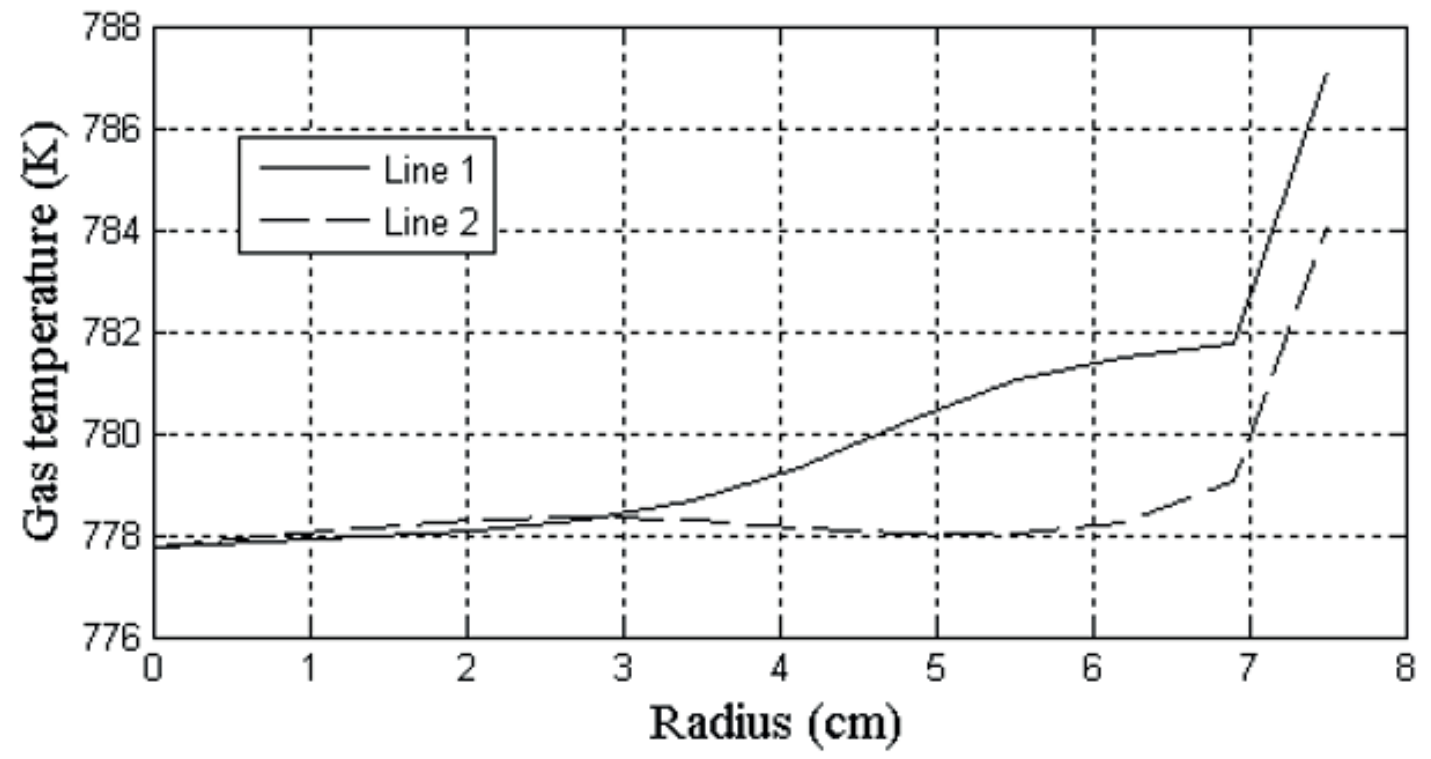

Figure 19. Radial temperature profile. 


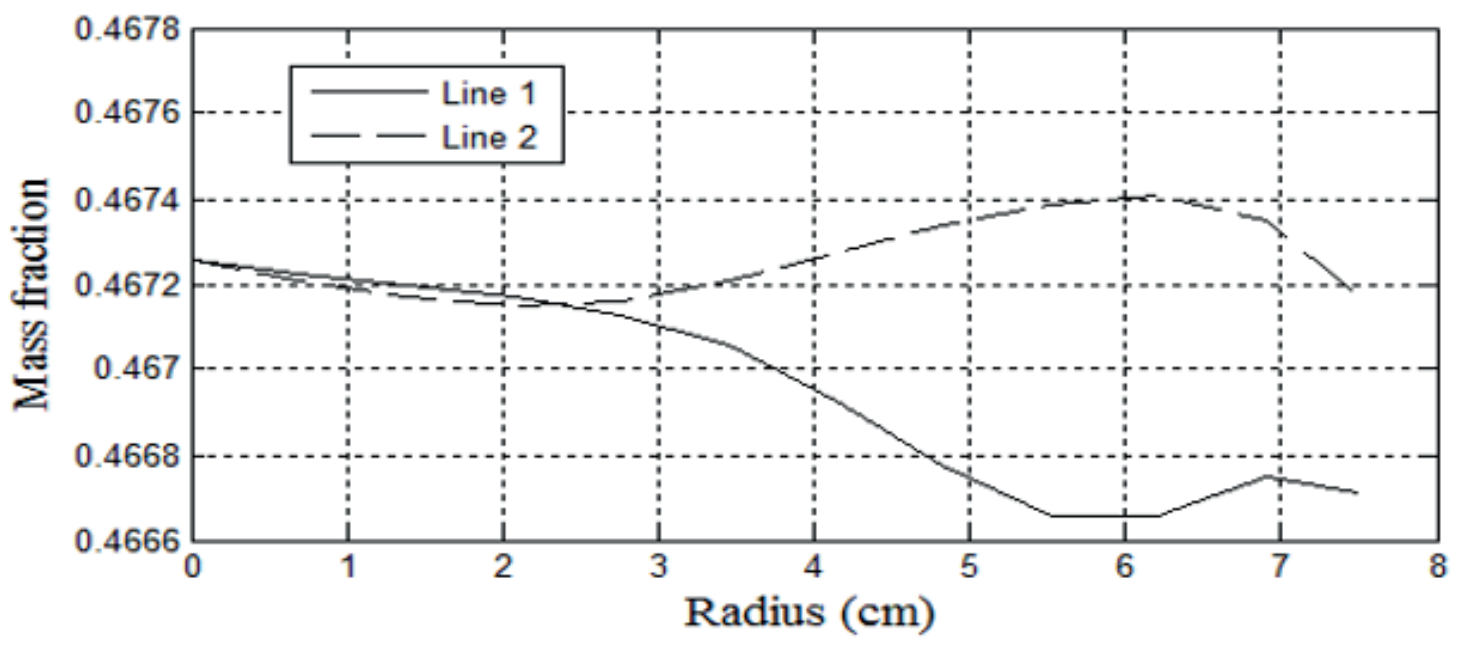

Figure 20. Radial mass fraction of EDC profile.

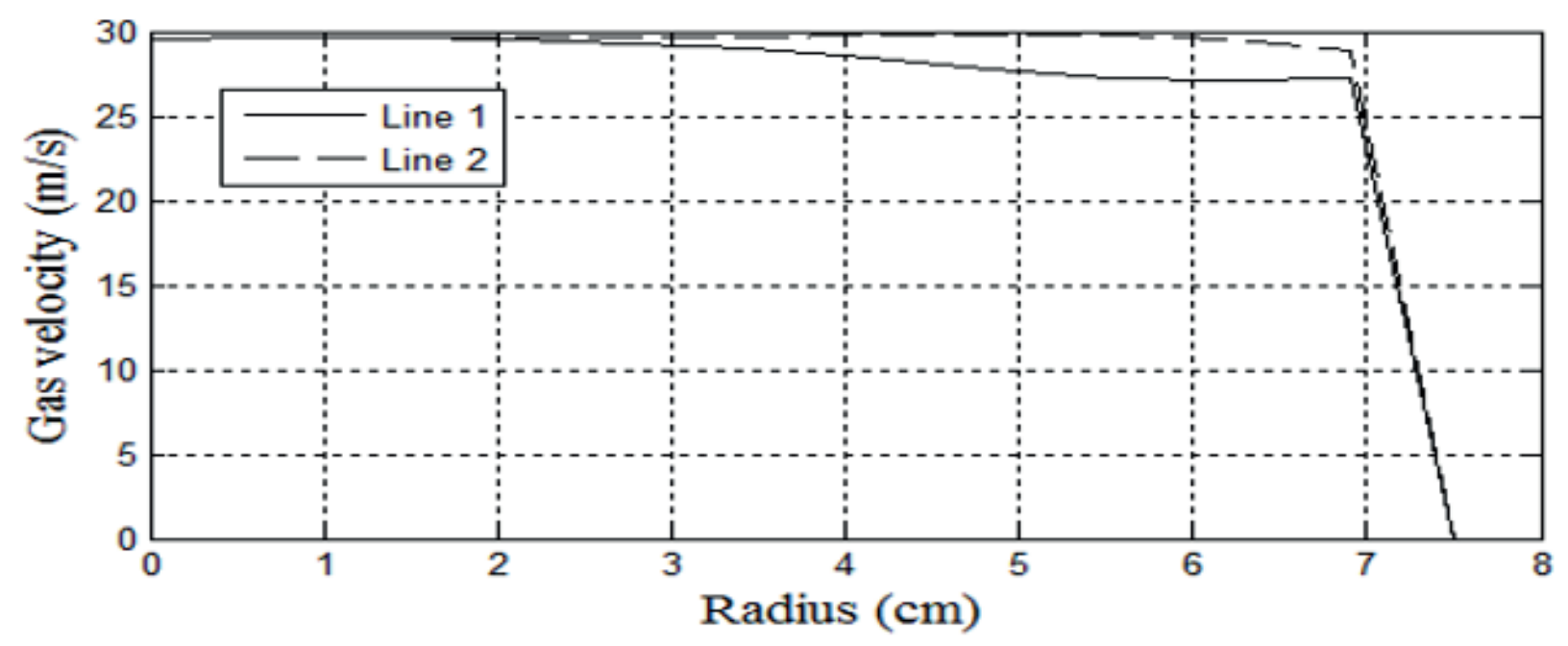

Figure 21. Velocity profile in the radial direction.

the 1-D model can be used because it has the advantage of fast response, while the CFD is more suitable for reactor design where the understanding of the detailed behaviour of the reactor might improve the reactor performance.

The results show an increase in the velocity along the reactor, which reduces the residence time, causing a reduction in EDC conversion.

A velocity profile at the reactor outlet is identical to a power law model as expected for turbulent flow in pipes $\left(\operatorname{Re}=3.6180 \times 10^{6}\right)$.

The results show that the radial gradients are important only close to the wall, sugesting that an 1-D model could be suitable for modeling the reactor of an EDC furnace, even though it is not an ideal plug flow reactor. This is corroborated by comparing the results from CFD to the results from the 1-D model.

As a contribution of this work, a new treatment for the wall boundary condition was proposed and successfully implemented in order to eliminate the mesh in the tube wall. The heat transfer model used to represent the heat supplied by the furnace, implemented as a wall boundary condition, has been shown to be adequate for modeling the EDC cracking reactor with the advantage of low computational cost.

In conclusion, the CFD model developed in this work is useful as a guide for the design, while the 1-D model is adequate for optimization of EDC thermal cracking furnaces. 


\section{NOMENCLATURE}

\begin{tabular}{|c|c|}
\hline$A_{j}$ & Pre-exponential factor $\left(\mathrm{s}^{-1}\right)$ \\
\hline$A_{s}$ & External surface area of the reactor $\left(\mathrm{m}^{2}\right)$ \\
\hline$A_{p}$ & Furnace wall area $(\mathrm{m} 2)$ \\
\hline$C_{E D C}$ & Molar concentration of EDC $\left(\mathrm{mol} / \mathrm{m}^{3}\right)$ \\
\hline$C_{p i}$ & Heat capacity at constant pressure $(\mathrm{kJ} / \mathrm{kgK})$ \\
\hline $\mathrm{D}$ & Internal diameter of the reactor $(\mathrm{m})$ \\
\hline $\mathrm{E}_{\mathrm{a}}$ & Activation energy $(\mathrm{kJ} / \mathrm{kmol})$ \\
\hline $\mathrm{F}_{\mathrm{ps}}^{\mathrm{a}}$ & $\begin{array}{l}\text { View factor of the furnace wall to the outer } \\
\text { surface of the reactor (-) }\end{array}$ \\
\hline $\mathrm{F}_{\mathrm{sp}}$ & $\begin{array}{l}\text { View factor of the outer surface of the reactor } \\
\text { to the furnace wall (-) }\end{array}$ \\
\hline$\vec{g}$ & Gravity $\left(\mathrm{m} / \mathrm{s}^{2}\right)$ \\
\hline$h_{r}$ & $\begin{array}{l}\text { Coefficient of heat transfer by radiation } \\
\left(\mathrm{W} / \mathrm{m}^{2} \mathrm{~K}\right)\end{array}$ \\
\hline $\mathrm{H}_{\mathrm{f}}$ & Enthalpy of formation $(\mathrm{kJ} / \mathrm{mol})$ \\
\hline$K^{1}$ & kinetic constant $\left(\mathrm{s}^{-1}\right)$ \\
\hline $\mathrm{k}_{\mathrm{M}}$ & $\begin{array}{l}\text { Thermal conductivity of the fluid misture } \\
(\mathrm{W} / \mathrm{mK})\end{array}$ \\
\hline $\mathrm{k}_{\mathrm{w}}$ & $\begin{array}{l}\text { Thermal conductivity of the reactor wall } \\
(\mathrm{W} / \mathrm{mK})\end{array}$ \\
\hline $\mathrm{P}$ & Pressure $\left(\mathrm{N} / \mathrm{m}^{2}\right)$ \\
\hline q & Heat flux $\left(\mathrm{W} / \mathrm{m}^{2}\right)$ \\
\hline $\mathrm{r}_{\mathrm{s}}$ & External radius of the reactor $(\mathrm{m})$ \\
\hline$r_{\text {in }}$ & Internal radius of the reactor $(\mathrm{m})$ \\
\hline $\mathrm{R}_{\mathrm{e}}$ & Reynolds number (-) \\
\hline$R_{i}$ & $\begin{array}{l}\text { Reaction rate per unit volume of the component } \\
i\left(\mathrm{~kg} / \mathrm{m}^{3} \mathrm{~s}\right)\end{array}$ \\
\hline $\mathrm{R}$ & Ideal gas constant $(\mathrm{J} / \mathrm{molK})$ \\
\hline $\mathrm{R}_{\mathrm{w}}$ & Thermal resistance of the wall $(\mathrm{K} / \mathrm{W})$ \\
\hline $\mathrm{S}$ & Distance between tubes (m) \\
\hline$S_{E}$ & Source of energy chemical reactions $\left(\mathrm{J} / \mathrm{m}^{3} \mathrm{~s}\right)$ \\
\hline$t$ & Time (s) \\
\hline $\mathrm{T}$ & Process gas temperature $(\mathrm{K})$ \\
\hline $\mathrm{T}_{\mathrm{p}}$ & Temperature of the firebox wall $(\mathrm{K})$ \\
\hline $\mathrm{T}_{\mathrm{s}}$ & $\begin{array}{l}\text { Temperature of the outer surface of the } \\
\text { reactor }(\mathrm{K})\end{array}$ \\
\hline $\mathrm{T}_{\mathrm{w}}$ & $\begin{array}{l}\text { Temperature of the inner surface of the } \\
\text { reactor }(\mathrm{K})\end{array}$ \\
\hline$\vec{v}$ & Velocity vector (m/s) \\
\hline $\mathrm{Y}_{\mathrm{i}}$ & Mass fraction of component A (-) \\
\hline
\end{tabular}

\section{Greek letters}

$\triangle C p \quad$ Variation of heat capacity $(\mathrm{kJ} / \mathrm{kmol})$

$\Delta H_{f i} \quad$ Variation of the enthalpy of formation $(\mathrm{kJ} / \mathrm{kmol})$

$\Delta H r \quad$ Variation of the enthalpy of reaction $(\mathrm{kJ} / \mathrm{kmol})$

$\epsilon \quad$ Emissivity function (-)

$\varepsilon_{\mathrm{s}} \quad$ Emissivity of the surface of the reactor (-)

$\varepsilon_{\mathrm{p}} \quad$ Furnace wall emissivity (-)

$\mu_{\text {eff }} \quad$ Effective viscosity $(\mathrm{kg} / \mathrm{ms})$

$\rho \quad$ specific mass $\left(\mathrm{kg} / \mathrm{m}^{3}\right)$

$\sigma \quad$ Stefan-Boltzmann constant $\left(\mathrm{W} / \mathrm{m}^{2} \mathrm{~K}^{4}\right)$
$\Gamma_{\mathrm{im}}$ Effective mass difusivity of the component $\mathrm{i}$ in the mixture $(\mathrm{kg} / \mathrm{ms})$

$\Phi_{f r} \quad$ Heat generation due to fluid friction $\left(\mathrm{J} / \mathrm{m}^{3} \mathrm{~s}\right)$

$\lambda_{\text {eff }}$ Effective thermal conductivity $(\mathrm{W} / \mathrm{mK})$

$\begin{array}{ll}\text { Subscripts } \\ \mathrm{i} & \text { Component } \\ \mathrm{j} & \text { Reaction } \\ \mathrm{s} & \text { External surface of the reactor } \\ \text { eff } & \text { Effective } \\ \mathrm{EDC} & 1,2 \text {-dichloroethane } \\ \mathrm{E} & \text { Energy } \\ \text { in } & \text { Internal } \\ f & \text { Formation } \\ w & \text { inner surface of the reactor }\end{array}$

\section{ACKNOWLEDGMENTS}

The authors are grateful to the National Council for Scientific and Technological Development of Brazil (CNPq) and Braskem S. A. for their financial and technical support, respectively.

\section{REFERENCES}

ANSYS CFX-Solver Theory Guide. ANSYS Inc.,Canonsburg, United States (2009).

Bird, R.B., Stewart, W.E. and Lightfoot, E.N. Transport Phenomena. 2nd ed. John Wiley \& Sons (2002).

Borsa, A. G. Industrial Plant/Laboratory Investigation and Computer Modeling of 1,2-Dichloroethane Pyrolysis. Ph.D. Dissertation, Colorado School of Mines, Golden, CO (1999).

Choi, B. K.; Oh, S.; Kim, W.; Yi, J. Simulation of the Effect of $\mathrm{CCl} 4$ on the Ethylene Dichloride Pyrolysis Process. Industrial Engineering Chemistry Research; vol. 40, p. 4040-4049 (2001).

Fogler, H. S. Elements of Chemical Reaction Engineering, Prentice Hall International Series, 3rd Edition (2000).

Hector Zambrano, Leonardo Di G. Sigalotti, Franklin Pena-Polo, Leonardo Trujillo, Turbulent models of oil flow in a circular pipe with sudden enlargement, Applied Mathematical Modelling, vol. 39, s. 67116724, Elsevier (2015).

Incropera, F. P., Dewitt, D. P., Bergman, T. L., Lavine, A. S. Introduction to Heat Transfer, 5th Edition, John Wiley \& Sons (2007).

Jones, W. P., and B.E. Launder, "The Prediction of Laminarization with a Two-Equation Model of Turbulence," A M J , 15, 301 (1972). 
Li, C.; Hu, G. ;Zhong, W. ;He, W.; Du, Wenli; Qian, F.; Coke Deposition Influence Based on a Run Length Simulation of a 1,2-Dichloroethane Cracker. Industrial \& Engineering Chemistry Research., 52 (49), 17501175162013.

Li, C. ;Hu, G. ;Zhong,W. ;Hui, C.; Qian, F.; Comprehensive Simulation and Optimization of an Ethylene Dichloride Cracker Based on the 1-D model Lobo-Evans Method and Computational Fluid Dynamics. Industrial \& Engineering Chemistry Research., 52 (49), 1750117516 (2012).

Oprins, A.J.M. and Heynderickx, G.J., Calculation of three-dimensional flow and pressure fields in cracking furnaces. Chemical Engineering Science, 58(21), 4883-4893 (2003).

Panjapornpon, C.; Limpanachaipornkul, P.; Charinpanitkul, T., Control of coupled PDEs-ODEs using inputoutput linearization: Application to a cracking furnace. Chemical Engineering Science, 75, 144-151 (2012).

Plehiers, P. M.; Geert, C.R.; Froment, G. F. Simulation of the Run Length of an Ethane Cracking Furnace. Industrial Engineering Chemistry Research, 29, 636641 (1990).

Plehiers, P. M.; Reyniers, G. C.; Froment, G. F. Simulation ofthe Run Length of an Ethane Cracking Furnace. Ind. Eng. Chem. Res., 29, 636-641 (1990).

Ranzi, E.; Dente, M.; Rovaglio, M.; Faravelli, T.; Karra, S. B.Pyrolysis and Chlorination of Small Hydrocarbons,
Chemical Engineering Communication, 117, 17-39 (1992).

Schirmeister, R.; Kahsnitz, J.; Trager, M., Influence of EDC Cracking Severity on the Marginal Costs of Vinyl Chloride Production. Ind. Eng. Chem. Res., 48, 28012809 (2009).

Stegowski, Z., Furman, L., Su'ud, Z., Kurniadi, R., Waris, A., \& Abidin, Z. (2013). Dispersion determination in a turbulent pipe flow using radiotracer data and CFD analysis. Computers \& Fluids, 79, 77-81 (2013).

Sundaram, K. M.; Froment, G. F. Kinetics of coke deposition in the thermal cracking of propane.Chemical Engineering Science, 34, 635-644 (1979).

Xingying, L.; Chunming, X.; Jinsen, G.; Hongmei, Z. A New Mathematical Simulation Approach for Thermal Cracking Furnace Studies. Petroleum Science, 2 (2004).

Yaws, C. L.. Chemical Properties Handbook, McGrawHill (1999).

Zhang, N., Tong, Q. I. U., and Bingzhen, C., CFD simulation of propane cracking tube using detailed radical kinetic mechanism. Chinese Journal of Chemical Engineering, 21(12), 1319-1331 (2013).

Yang, Y. and Cao, B., Two-Dimensional Modeling of 1,2-Dichloroethane Cracking Tubular Reactor. Journal of Chemical Industry and Engineering (China), 53(10), 1046-1050 (2002). 